PАСS: 12.15. \pm Y, 12.60. \pm I, 14.80.ВN, 14.80.СР УДК 539.19

\title{
SENSING HYPERFINE-STRUCTURE, ELECTROWEAK INTERACTION AND PARITY NON-CONSERVATION EFFECT IN HEAVY ATOMS AND NUCLEI: NEW NUCLEAR QED APPROACH
}

\author{
O. Yu. Khetselius, Yu. V. Dubrovskaya, Yu. M. Lopatkin, A. A. Svinarenko \\ I. I. Mechnikov Odessa National University, Odessa \\ Odessa National Polytechnical University, Odessa \\ Odessa State Environmental University, Odessa \\ Sumy National University, Sumy
}

\begin{abstract}
SENSING HYPERFINE-STRUCTURE, ELECTROWEAK INTERACTION AND PARITY NONCONSERVATION EFFECT IN HEAVY ATOMS AND NUCLEI: NEW NUCLEAR QED APPROACH
\end{abstract}

\section{O. Yu. Khetselius, Yu. V. Dubrovskaya, Yu. M. Lopatkin, A. A. Svinarenko}

Abstract. It is presented the new theoretical approach for sensing hyperfine structure parameters, scalar-pseudoscalar interaction constant and parity non-conservation effect in heavy atomic and nuclear systems, based on the combined QED perturbation theory formalism and relativistic nuclear mean-field theory. Results of estimating these constants in different heavy atoms and nuclei are presented.

Keywords: hyperfine structure, electroweak interaction, parity non-conservation, heavy atoms and nuclei, nuclear-QED theory

\section{ПРО ДЕТЕКТУВАННЯ ПАРАМЕТРІВ ПОНАДТОНКОІ СТРУКТУРИ, ЕЛЕКТРОСЛАБКОЇ ВЗАЕМОДІЇ ТА ЕФЕКТУ НЕЗБЕРЕЖЕННЯ ПАРНОСТІ У ВАЖКИХ АТОМАХ ТА ЯДРАХ: ЯДЕРНИЙ КЕД ПІДХІД}

\section{О. Ю. Хецеліус, Ю. В. Дубровська, А. А. Свинаренко}

Анотація. Розглянутий новий теоретичний підхід до визначення параметрів понад тонкої структури, електрослабкої взаємодії, сталої скаляр - псевдоскалярної взаємодії та ефекту незбереження парності у важких атомних та ядерних системах, який базується на ядерноКЕД теорії збурень та релятивістській моделі середнього поля. Наведені результати розрахунку шуканих параметрів у різноманітних важких атомах та ядрах.

Ключові слова: надтонка структура, електрослабка взаємодія, незбереження парності, важкіх атоми та ядра, ядерно-КЕД теорія

\section{О ДЕТЕКТРОВАНИИ ПАРАМЕТРОВ СВЕРХТОНКОЙ СТРУКТУРЫ , ЭЛЕКТРОСЛАБОГО ВЗАИМОДЕЙСТВИЯ И ЭФФЕКТА НЕСОХРАНЕНИЯ ТОЧНОСТИ В ТЯЖЕЛЫХ АТОМАХ И ЯДРАХ: НОВЫЙ ЯДЕРНО-КЭД ПОДХОД}

\section{О. Ю. Хещелиус, Ю. В. Дубровская, А. А. Свинаренко}

Аннотация. Представлен новый теоретический подход к определению параметров сверхтонкой структуры, электрослабого взаимодействия, константы скаляр - псевдоскалярного взаимодействия и эффекта несохранения четности в тяжелых атомных и ядерных системах, базирующийся на ядерно-КЭД теории возмущений и релятивистской ядерной модели среднего поля. Приведены результаты расчета искомых параметров в различных атомах и ядрах.

Ключевые слова: сверхтонкая структура, электрослабое взаимодействие, несохранение четности, тяжелые атомы и ядра, ядерно-КЭД теория 


\section{Introduction}

A development of the effective nuclear schemes and technologies for sensing different nuclear properties, creation of the corresponding nuclear sensors are of a great importance in the modern nuclear physics and sensor science. It allows further developing the modern as atomic and as nuclear theories too. In last years a studying the spectral lines hyperfine structure (hfs) for heavy elements and multicharged ions is of a great interest for further development as atomic and nuclear theories [1-44]. The multi-configuration relativistic Hartree-Fock (RHF) and Dirac-Fock (MCDF) approximation (c.f. $[3,4,17,26]$ is the most reliable version of calculation for multi-electron systems with a large nuclear charge; in these calculations one- and twoparticle relativistic effects are taken into account practically precisely. The next important step is an adequate account for the nuclear and QED corrections. This topic has been a subject of intensive theoretical and experimental interest (c.f. $[3,4]$ ). From the other side, the parity violation (non-conservation) experiments in atomic physics provide an important possibility to deduce information on the Standard Model independent of high-energy physics experiments [1-3]. The recent LEP experiments are fulfilled $[1,2]$, that yield extremely accurate values for Z-boson properties. Although the spectacular experimental achievements of particle physics in the last decade have strengthened the Standard Model (SM) as an adequate description of nature, they have also revealed that the SM matter represents a mere $5 \%$ or so of the energy density of the Universe, which clearly points to some physics beyond the SM despite the desperate lack of direct experimental evidence. The sector responsible for the spontaneous breaking of the SM electroweak symmetry is likely to be the first to provide experimental hints for this new physics. The detailed review of these topics can be found in refs. [1-6], in particular, speech is about brief introducing the SM physics and the conventional Higgs mechanism and a survey of recent ideas on how breaking electroweak symmetry dynamics can be explained. Further one could remind that the observation of a static electric dipole moment of a many-electron atom which violates parity, $\mathrm{P}$, and time reversal, $\mathrm{T}$, symmetry, represents a great fundamental interest in searching for a new physics beyond the Standard model of elementary particles [1-10]. The interaction mixes parity of atomic states and also induces a static electric dipole moment of the atom. As it is indicated above, different methods have been used in calculation of the hyperfine structure parameters, S-PS constant, parity non-conservation effect. Nevertheless, one can state that the consistent theory is absent hitherto.

The most popular multiconfiguration DiracFock (MCDF) method for calculating parity and time reversal symmetry violations in many-electron atoms has some serious disadvantages $[3,17,26]$. This fact has stimulated a development of different versions of the many-body perturbation theory (PT), namely, the PT with RHF and DF zeroth approximations, QED-PT and nuclear QED PT [143]. In present paper the new theoretical approach, namely, nuclear QED PT is used for detection of the hyperfine structure and electroweak interaction parameters, scalar-pseudoscalar interaction constant and parity non-conservation (PNC) effect in atomic system. In fact the N-QED PT is based on the combining ab initio QED PT formalism and nuclear relativistic middle-field (RMF) model and allows to fulfil studying the spectra for atomic systems with an account of the relativistic, correlation, nuclear, radiative effects [10,38-44]. The important feature is the correct accounting for the inter electron correlations, nuclear, Breit and QED radiative corrections. All correlation corrections of the second order and dominated classes of the higher orders diagrams are taken into account [10]. The results of studying the different atomic systems are presented.

\section{Nuclear-QED PT approach to hyperfine, electroweak interactions in heavy atoms, nuclei and parity-non-conservation transition amplitude}

The wave electron functions zeroth basis is found from the Dirac equation solution with potential, which includes the core ab initio potential, electric, polarization potentials of nucleus. All correlation corrections of the second and high orders of PT (electrons screening, particle-hole interaction etc.) are accounted for [10]. The concrete nuclear model is based on the relativistic mean-field (RMF) model for the ground-state calculation of the nucleus. Though we have no guaranty that these wave-functions yield a close approximation to nature, the success of the RMF approach supports our choice [35]. These wave functions do not suffer from known deficiencies of other approaches, e.g., the wrong asymptotics of wave functions obtained in a harmonic 
oscillator potential. The RMF model has been designed as a renormalizable meson-field theory for nuclear matter and finite nuclei. The realization of nonlinear self-interactions of the scalar meson led to a quantitative description of nuclear ground states. As a self-consistent mean-field model (for a comprehensive review see ref. [35]), its ansatz is a Lagrangian or Hamiltonian that incorporates the effective, in-medium nucleon-nucleon interaction. Recently the self-consistent models have undergone a reinterpretation, which explains their quantitative success in view of the facts that nucleons are composite objects and that the mesons employed in RMF have only a loose correspondence to the physical meson spectrum. They are seen as covariant Kohn-Sham schemes and as approximations to the true functional of the nuclear ground state. As a Kohn-Sham scheme, the RMF model can incorporate certain ground-state correlations and yields a ground-state description beyond the literal meanfield picture. RMF models are effective field theories for nuclei below an energy scale of $1 \mathrm{GeV}$, separating the long- and intermediate-range nuclear physics from short-distance physics, involving, i.e., shortrange correlations, nucleon form factors, vacuum polarization etc, which is absorbed into the various terms and coupling constants. As it is indicated in refs. $[6,20]$ the strong attractive scalar $(S:-400 \mathrm{MeV})$ and repulsive vector $(V:+350 \mathrm{MeV})$ fields provide both the binding mechanism $(S+V:-50 \mathrm{MeV})$ and the strong spin-orbit force $(S-V:-750 \mathrm{MeV})$ of both right sign and magnitude $[35,44]$.

In our approach we have used so called NL3NLC and generalized Ivanov et al approach (see details in refs. $[4,12]$ ), which are among the most successful parameterizations available. Further one can write the Dirac-Fock -like equations for a multielectron system $\{$ core- $n l j\}$. Formally they fall into one-electron Dirac equations for the orbitals $n l j$ with potential: $\quad V(r)=2 V(r \mid S C F)+V(r \mid n l j)+V_{e x}+V(r \mid R)$. Radial parts $F$ and $G$ of two components of the Dirac function for electron, which moves in the potential $V(r, R)$ are defined by solution of the Dirac equations (PT zeroth order). The general potential includes the electrical and polarization potentials of a nucleus. The part $V_{e x}$ of the general potential accounts for exchange inter-electron interaction. The exchange effects are accounted for in the first two PT orders. The core electron density is defined by iteration algorithm within QED procedure [4]. The radiative QED (the self-energy part of the Lamb shift and the vacuum polarization contribution) are accounted for within the QED formalism [4]. The hyperfine structure constants are defined as follows. The interaction Hamiltonian has the standard form:

$$
H_{I}=e \bar{j}_{e}^{\mu} \bar{A}_{\mu}+e \bar{J}_{N}^{\mu} \bar{A}_{\mu}
$$

where $j_{e}^{\mu}, j_{N}^{\mu}$ are Lorentz covariant current operators for the electron and the nucleus:

$$
\begin{gathered}
\bar{j}_{e}^{\mu}=\overline{\bar{\psi}}_{e} \gamma^{\mu} \widehat{\psi}_{e} \\
\bar{J}_{N}^{\mu}=\frac{1+\tau}{2} \widehat{\bar{\psi}}_{N} \gamma^{\mu} \bar{\Psi}_{N}+\frac{\lambda}{2 M} \partial_{v}\left(\overline{\bar{\Psi}}_{N} \sigma^{\mu \nu} \bar{\Psi}_{N}\right) .
\end{gathered}
$$

Here $\sigma^{\mu v}=\frac{1}{2}\left[\gamma^{\mu}, \gamma^{\nu}\right]$. The rest notations are standard. Using the first-order perturbation based on the S-matrix method one can get the expression for the hyperfine structure. Usually the transverse part of the photon propagator is defined as follows:

$$
\frac{1}{4 \pi} \frac{\delta_{12}}{|x 1-x 2|} \text {. }
$$

But more consistent scheme is proposed in refs. $[10,44]$ and consist in using (after transition to notime diagrams) the following expression:

$$
\frac{1}{4 \pi} \frac{1}{|x 1-x 2|} \exp \left(i|\omega| x_{12}\right)\left(1-\alpha_{1} \alpha_{2}\right)
$$

So, it allows to take into account the Breit effect (magnetic interaction). Further, as usually, the reduced matrix element in (6) can be divided on the electron part and on the Dirac part and the anomalous part for a nucleus. In order to define all parts the corresponding relativistic wave functions of the electron and single-particle states of a nucleus are required (look above).

Further let us consider the elements of calculating the PNC transition amplitude. The dominative contribution to the PNC amplitude is provided by the spin-independent part of the operator for a weak interaction, which should be added to the atomic Hamiltonian [5]:

$$
H=H_{a t}+\mu \sum_{j} H_{W}(j), H_{W}^{1}=\frac{G}{2 \sqrt{2}} Q_{W} \gamma_{5} \rho(r),
$$

Where -is the Fermi constant of the weak interaction, $\gamma_{5}$-is the Dirac matrice, $\rho(r)$-is a density of the charge distribution in a nucleus and $Q_{W}$ is a weak charge of a nucleus, linked with number of neutrons $\mathrm{N}$ and protons $\mathrm{Z}$ and the Weinberg angle $\theta_{\mathrm{w}}$ in the Standard model (c.f. [1-3]):

$$
Q_{W}=Z\left(1-4 \sin ^{2} \theta_{W}\right)-N \text {. }
$$

With account for the radiative corrections, equation (7) can be rewritten as [5,18]: 


$$
\begin{aligned}
Q_{W}= & \left\{Z\left(1-[4.012 \pm 0.010] \sin ^{2} \theta_{W}\right)-N\right\} \times \\
& \times(0.9857 \pm 0.0004)(1+0.0078 T)
\end{aligned}
$$

$$
\left.\sin ^{2} \theta_{W}=0.2323+0.00365 S-0.00261 T\right)
$$

The parameters $\mathrm{S}, \mathrm{T}$ parameterize the looped corrections in the terms of conservation (S) and violation (T) of an isospin. The spin-dependent contribution to the PNC amplitude has three distinct sources: the nuclear anapole moment ((that is considered as an electromagnetic characteristics of system, where the PNC takes a place; generally speaking, speech is about the arisen spin structure and the magnetic field distribution is similar to the solenoid field), the $Z$-boson exchange interaction from nucleon axial-vector currents $\left(A_{n} V_{e}\right)$, and the combined action of the hyperfine interaction and spin-independent $Z$-boson exchange from nucleon vector $\left(V_{n} A_{e}\right)$ currents $[7,9,34]$. The anapole moment contribution strongly dominates. The abovementioned interactions can be represented by the Hamiltonian

$$
H_{W}^{i}=\frac{G}{\sqrt{2}} k_{i}(\alpha \cdot I) \rho(r),
$$

where $\mathrm{k}(\mathrm{i}=\mathrm{a})$ is an anapole contribution, $\mathrm{k}(\mathrm{i}=2)=\mathrm{k}_{\mathrm{z} 0}-$ axial-vector contribution, $\mathrm{k}(\mathrm{i}=\mathrm{kh})=\mathrm{k}_{\mathrm{Ow}}$ is a contribution due to the combined action of the hyperfine interaction and spin-independent $Z$ exchange . The estimate of the corresponding matrix elements is in fact reduced to the calculation of the integrals as [10]:

$$
\begin{gathered}
<i\left|H_{W}^{1}\right| j>=i \frac{G}{2 \sqrt{2}} Q_{W} \delta_{k_{i}-k_{j}} \delta_{m_{i} m_{j}} \times \\
\times \int_{0}^{\infty} d r\left[F_{i}(r) G_{j}(r)-G_{i}(r) F_{j}(r)\right] \rho(r) .
\end{gathered}
$$

The reduced matrix element is as follows:

$$
\begin{gathered}
<i\left\|H_{W}^{1}\right\| j>=i \frac{G}{2 \sqrt{2}} Q_{W} \times \\
\times \int_{0}^{\infty} d r\left[F_{i}(r) G_{j}(r)-G_{i}(r) F_{j}(r)\right] \rho(r) .
\end{gathered}
$$

Further the general expression for the corresponding PNC amplitude for $\mathrm{a}-\mathrm{b}$ transition is written as follows:

$$
\begin{gathered}
<a|P N C| b>= \\
=-\sum_{n}\left[\frac{<b\left|e \alpha_{v} A^{v}\right| n><n\left|H_{W}^{(1)}\right| a>}{\varepsilon_{a}-\varepsilon_{n}}+\right. \\
+\frac{<b\left|H_{W}^{(1)}\right| n><n\left|e \alpha_{v} A^{v}\right| a>}{\varepsilon_{b}-\varepsilon_{n}} .
\end{gathered}
$$

The corresponding spin-dependent PNC contribution is :

$$
\begin{gathered}
<a|P N C| b>^{s d}=k_{a}<a|P N C| b>^{(a)}+ \\
+k_{2}<a|P N C| b>^{(2)}+k_{h f}<a|P N C| b>^{(h f)}
\end{gathered}
$$

where

$$
\begin{aligned}
& <a|P N C| b>^{(h f)}= \\
& \sum_{\substack{m \neq a \\
n \neq a}} \frac{<a\left|H_{W}^{(1)}\right| n><n\left|H_{W}^{(h f)}\right| m><m\left|e \alpha_{v} A^{v}\right| b>}{\left(\varepsilon_{a}-\varepsilon_{m}\right)\left(\varepsilon_{a}-\varepsilon_{n}\right)}+ \\
& +\sum_{\substack{m \neq a \\
n \neq a}} \frac{<a\left|H_{W}^{(h f)}\right| n><n\left|H_{W}^{(1)}\right| m><m\left|e \alpha_{v} A^{v}\right| b>}{\left(\varepsilon_{a}-\varepsilon_{m}\right)\left(\varepsilon_{a}-\varepsilon_{n}\right)} \\
& +\sum_{\substack{m \neq a \\
n \neq b}}^{<a\left|H_{W}^{(1)}\right| m><m\left|e \alpha_{v} A^{v}\right| n><n\left|H_{W}^{(h f)}\right| m>}+ \\
& +\sum_{\substack{m \neq a \\
n \neq b}} \frac{<a\left|H_{W}^{(h f)}\right| m><m\left|e \alpha_{v} A^{v}\right| n><n\left|H_{W}^{(h f)}\right| b>}{\left(\varepsilon_{a}-\varepsilon_{m}\right)\left(\varepsilon_{b}-\varepsilon_{n}\right)} \\
& +\sum_{\substack{m \neq b \\
n \neq b}}^{<a\left|e \alpha_{v} A^{v}\right| n><n\left|H_{W}^{(1)}\right| m><m\left|H_{W}^{(h f)}\right| b>}+ \\
& +\sum_{\substack{m \neq b \\
n \neq b}} \frac{<a\left|e \alpha_{v} A^{v}\right| n><n\left|H_{W}^{(h f)}\right| m><m\left|H_{W}^{(1)}\right| b>}{\left(\varepsilon_{b}-\varepsilon_{m}\right)\left(\varepsilon_{b}-\varepsilon_{n}\right)}+\left(\varepsilon_{b}-\varepsilon_{n}\right) \\
& -<a\left|H_{W}^{(h f)}\right| a>\sum_{m \neq a} \frac{<a\left|H_{W}^{(1)}\right| m><m\left|e \alpha_{v} A^{v}\right| b>}{\left(\varepsilon_{a}-\varepsilon_{m}\right)^{2}}- \\
& -\sum_{n \neq b} \frac{<a\left|e \alpha_{v} A^{v}\right| n><n\left|H_{W}^{(1)}\right| b>}{\left(\varepsilon_{b}-\varepsilon_{n}\right)^{2}}<b\left|H_{W}^{(h f)}\right| b>.
\end{aligned}
$$

Here the following notations are used: $|a>=| a I F_{F} M_{F}>,|b>=| b I F_{I} M_{I}>, I-$ spin of a nucleus, $F_{I, F}$-is a total momentum of an atom and $M-$ its $\mathrm{z}$ component (I,F are the initial and final states). It should be noted the expressions for the matrix elements $\langle a|P N C| b\rangle^{(a)},\langle a|P N C| b\rangle^{(2)}$ are similar to equation (14).

The possible source of the electric dipole moment in the paramagnetic atoms is the scalar-pseudoscalar (S- PS) interaction between electrons and a nucleus, which is defined as $[1,2,11]$ :

$$
\hat{H}_{S-P S}=i \frac{G_{F}}{2} C_{S_{-} P S} A \sum_{j=1}^{N} \beta_{j} \gamma_{j}^{5} \rho\left(r_{j}\right) .
$$

Here $G_{\mathrm{F}}$ is the Fermi constant, $C_{\mathrm{S}-\mathrm{PS}}$ is the $\mathrm{S}-\mathrm{PS}$ interaction constant, $\mathrm{A}$ is the mass number, $\beta$ and $\gamma^{5}$ are the Dirac matrices and $\rho(r)$ is the nuclear density function. The full description of the corresponding matrix elements and other details of the general method and PC code are presented in refs. [4,10,39-44]. 


\section{Results and conclusions}

As the first studying objects, we have considered the nuclei of isotopes of ${ }^{133} \mathrm{Cs}$ and Cs-like ion of barium. We carried out calculation (the SuperatomISAN and RMF-G package $[17,18]$ are used) the hyperfine structure (hfs) parameter for $\mathrm{Cs}$ and $\mathrm{Ba}^{+}$ isotopes. In table 1 the experimental $\left(\mathrm{A}^{\mathrm{Exp}}\right)$ and our $\left(\mathrm{A}^{\mathrm{N}-\mathrm{Qed}}\right)$ data for magnetic dipole constant $\mathrm{A}(\mathrm{MHz})$ for valent states of ${ }^{133} \mathrm{Cs}\left(I=7 / 2, g_{i}=0.7377208\right)$ are presented. The calculation results within standard ( $\left.\mathrm{A}^{\mathrm{RHF}}\right) \mathrm{RHF}$ and RHF with account of the $2^{\text {nd }}$ and higher PT corrections, the MCDF approximation and QED formalism [26,32] are given too. In a whole the better agreement of our data with experimental ones in comparison with other data we explain by using the gauge-invariant relativistic orbital basis's and more correct account for correlation, nuclear, QED effects. In table 2 we present the results of calculating the hfs constant $A$ for different states of the
Cs-like ion of barium: $\left[5 \mathrm{p}^{6}\right] 6 \mathrm{~s}_{1 / 2}, 6 \mathrm{p}_{1 / 2}$. The following notations are used: $\mathrm{A}^{\mathrm{RCC}}-$ calculation by relativistic cluster-coupled (RCC) method; $\mathrm{A}^{\mathrm{DF}}-\mathrm{DF}$ method; $\mathrm{A}^{\mathrm{RHF}}-\mathrm{RHF}$ method [36,37] and $\mathrm{A}^{\mathrm{QED}}$ the QED calculation [32]; $A^{\mathrm{N}-\mathrm{Qed}}$ is the result of the present paper. In table 3 we listed the values of the hyperfine structure energy and magnetic moment (in nuclear magnetons) In ${ }^{209} \mathrm{~Pb},{ }^{207} \mathrm{Tl}$, calculated on the basis of different theoretical models [12-14]. The key quantitative factor of agreement between our theory and experimental data is connected with the correct accounting for the inter electron correlations, nuclear, Breit and QED radiative corrections (including magnetic moment distribution in a nucleus and nuclear corrections). The available values of the S-PS interaction constant in the different models for ${ }^{133} \mathrm{Cs}$ are as follows: $3.08998 \cdot 10^{-6}$ (MCDF by Gaigalas etal [11]); 2.24719.10-6 (Murthy-, Krause-Li-Hunter L.).

Table 1

The values $(\mathrm{MHZ})$ of the hfs constant $\mathrm{A}$ for valent states of ${ }^{133} \mathrm{Cs}$ : $\mathrm{A}^{\mathrm{Exp}}-$ experiment; $\mathrm{A}^{\mathrm{RHF}}, \mathrm{dA}^{\mathrm{RHF}}-\mathrm{RHF}$ calculation plus the second and higher PT orders contribution [26]; $\mathrm{A}^{\mathrm{QED}}-$ data [32]; $A^{\mathrm{N}-\mathrm{Qed}}-$ the present paper;

\begin{tabular}{|c|c|c|c|c|c|c|}
\hline State & $A^{\mathrm{MCDF}}$ & $A^{\mathrm{RHF}}$ & $A^{\mathrm{RHF}}+d A$ & $A^{\mathrm{Qed}}$ & $A^{\mathrm{N}-\mathrm{Qed}}$ & $A^{\mathrm{Exp}}$ \\
\hline $6 s_{1 / 2}$ & 1736,9 & 1426,81 & 2291,00 & 2294,45 & 2296,78 & $2298,16(13)$ \\
\hline $6 p_{1 / 2}$ & 209,6 & 161,09 & 292,67 & 292,102 & 292,118 & $291,90(9)$ \\
\hline
\end{tabular}

Theoretical and experimental data for hfs constant A in Cs-like ion Ba states (see text)

\begin{tabular}{|c|c|c|c|c|c|c|}
\hline State & $A^{E x p}$ & $A^{R C C}$ & $A^{D F}$ & $A^{R H F}$ & $A^{Q E D}$ & $A^{\mathrm{N}-\mathrm{Qed}}$ \\
\hline$\left[5 p^{6}\right] 6 s_{1 / 2}$ & 4018,87 & 4072,83 & 4193,02 & 4208,2 & 4014,52 & 4016,76 \\
\hline$\left[5 p^{6}\right] 6 p_{1 / 2}$ & 741,91 & 740,77 & 783,335 & --- & 742,96 & 742,01 \\
\hline
\end{tabular}

The hfs energy and magnetic moment (in nucl. magnetons) in ${ }^{209} \mathrm{~Pb}^{81+},{ }^{207} \mathrm{Tl}^{80+}[12-14]$

Table 3

\begin{tabular}{|c|c|c|}
\hline & ${ }^{207} \mathrm{Tl}^{80+}$ & ${ }^{209} \mathrm{~Pb}^{81+}$ \\
\hline Magn. moment $\left[\mu_{\mathrm{N}}\right]$ & HS NLC Tomaselli N-QED & HS NLC N-QED \\
\hline Theory & 1.87691 .87581 .64721 .8764 & $-1.4756-1.4714-1.4748$ \\
Exp. [14] & $1.8765(5)$ & $-1.4735(16)$ \\
\hline HFS $[\mathrm{eV}]$ & HS NLC Tomaselli N-QED & HS NLC N-QED \\
\hline$\Delta \mathrm{E}^{1} \mathrm{HFS}$ & $3,7213,7293,25923,5209$ & $0,00940,0110$ \\
\hline$\Delta \mathrm{E}_{\mathrm{QED}}$ & $-0,0201-0,0178-0,0207$ & $-1.698-1.692-1,6941$ \\
\hline Total & $3,7013,7083,25923,5002$ & \\
\hline
\end{tabular}

Our result is $2.76513 \cdot 10^{-6}$ (present paper). So, in a whole there is a physically reasonable agreement between the data of different theories. [10]. In table 4 there are listed the PNC amplitudes (in units of $10^{-11}$ iea $\left._{\mathrm{B}}\left(-\mathrm{Q}_{\mathrm{W}}\right) / \mathrm{N}\right)$, which are calculated by the different methods (without the Breit corrections): DF, RHF, MCDF, many-body perturbation theory (MBPT) and our nuclear-QED PT results (other data from refs. [25-34]). In table 5 we present the Breit correction (in units of $10^{-11}\left(-\mathrm{Q}_{\mathrm{W}}\right) / \mathrm{N}$ ) to the PNC amplitude, which are calculated by the different methods (without the Breit corrections): DF, RHF, MCDF, and our nuclear-QED PT results (other data from refs. [25-34]). 
PNC amplitudes (in units of $10^{-11} \mathrm{iea}_{\mathrm{B}}\left(-\mathrm{Q}_{\mathrm{w}}\right) / \mathrm{N}$ ), which are calculated by different methods (without the Breit corrections): DF, RHF, MCDF, MBPT and nuclear-QED PT .

\begin{tabular}{|c|c|c|c|c|c|c|c|c|c|}
\hline $\begin{array}{l}\text { Atom } \\
\text { Trans. }\end{array}$ & $\begin{array}{c}\text { Spin } \\
\text { of } \\
\text { Nucl. }\end{array}$ & $\begin{array}{c}\text { Nucl. } \\
\text { moment } \\
\mu_{\mathrm{N}}\end{array}$ & $\begin{array}{c}\text { Weak } \\
\text { charge } \\
\mathrm{Q}_{\mathrm{W}}\end{array}$ & $\begin{array}{l}\text { Radius } \\
(\mathrm{fm}) \text { of } \\
\text { nucleus }\end{array}$ & DF & RHF & MCDF & МBPT & $\begin{array}{c}\text { N-QED } \\
\text { PT }\end{array}$ \\
\hline $\begin{array}{l}{ }^{85} \mathrm{Rb} \\
5 \mathrm{~s}-6 \mathrm{~s}\end{array}$ & $5 / 2$ & 1.3534 & -44.75 & 4.246 & -0.110 & -0.138 & -0.134 & -0.135 & -0.132 \\
\hline $\begin{array}{l}{ }^{133} \mathrm{Cs} \\
6 \mathrm{~s}-7 \mathrm{~s}\end{array}$ & $7 / 2$ & 2.5826 & -73.19 & 4.837 & -0.741 & $\begin{array}{l}-0.926 \\
-0.897\end{array}$ & -0.904 & $\begin{array}{l}-0.906 \\
-0.908\end{array}$ & -0.903 \\
\hline $\begin{array}{l}{ }^{223} \mathrm{Fr} \\
7 \mathrm{~s}-8 \mathrm{~s}\end{array}$ & $3 / 2$ & 1.1703 & -128.08 & 5.640 & -13.72 & -16.63 & -15.72 & $\begin{array}{r}-15.56 \\
-15.80 \\
\end{array}$ & -15.54 \\
\hline $\begin{array}{l}{ }^{211} \mathrm{Fr} \\
7 \mathrm{~s}-8 \mathrm{~s}\end{array}$ & $9 / 2$ & 4.0032 & -116.23 & 5.539 & -12.51 & -15.16 & -14.34 & - & -14.17 \\
\hline
\end{tabular}

Table 5

The Breit correction (in units of $10^{-11}\left(-\mathrm{Q}_{\mathrm{w}}\right) / \mathrm{N}$ ) to the PNC amplitude, which are calculated by the different methods (without the Breit corrections): DF, RHF, MCDF, and our nuclear-QEDPT results (otherdatafrom refs. [25,29,33]).

\begin{tabular}{|c|c|c|c|c|}
\hline $\begin{array}{c}\text { Atom: Tran- } \\
\text { sition. }\end{array}$ & DF & RHF & MCDF & $\begin{array}{c}\text { N-QED } \\
\text { PT }\end{array}$ \\
\hline${ }^{133} \mathrm{Cs} 6 \mathrm{~s}-7 \mathrm{~s}$ & 0.0022 & 0.0018 & 0.0045 & 0.0049 \\
\hline${ }^{223} \mathrm{Fr} 7 \mathrm{~s}-8 \mathrm{~s}$ & 0.0640 & 0.0650 & 0.1430 & 0.1703 \\
\hline
\end{tabular}

Let us note that the radiative corrections to the PNC amplitude, provided by the vacuum-polariza- tion (VP) effect and the self-energy (SE) part are as follows: $\mathrm{E}_{\mathrm{PNC}}{ }^{-133} \mathrm{Cs}-\mathrm{VP}=0.38 \%, \mathrm{SE}=-0.74 \%$; ${ }^{223} \mathrm{Fr}-\mathrm{VP}=1.025 \%, \mathrm{SE}=-1.35 \%$. Further in table 6 we list the nuclear spin dependent corrections to the PNC ${ }^{133}$ Cs: 6s-7s amplitude $\mathrm{E}_{\mathrm{PNC}}$, calculated by different theoretical methods (in units of the $\mathrm{k}_{\mathrm{a}, 2, \mathrm{hf}}$ coefficient): MBPT, DF-PT, the shell model, N-QED PT (present paper) (from refs. [9,27,28,34]). In table 7 there are presented the estimated values of the weak charge $\mathrm{Q}_{\mathrm{W}}$ for different heavy atoms, predicted in different approaches (from refs. [18,27,28,34]).

Table 6

The nuclear spin-dependent corrections to the PNC ${ }^{133} \mathrm{Cs}$ : $6 \mathrm{~s}-7 \mathrm{~s}$ amplitude $\mathrm{E}_{\mathrm{PNC}}$, calculated by different methods (in units of $\mathrm{k}_{\mathrm{a}, 2, \mathrm{hf}}$ coeff.): MBPT, DF-PT, shell model, N-QED PT (see text).

\begin{tabular}{|l|c|c|c|c|}
\hline \multicolumn{1}{|c|}{ Correction } & MBPT & $\begin{array}{c}\text { Shell } \\
\text { model }\end{array}$ & DF & $\begin{array}{c}\text { N-QED } \\
\text { PT }\end{array}$ \\
\hline $\mathrm{K}($ sum $)$ & 0.1169 & 0.1118 & 0.112 & 0.1159 \\
\hline $\begin{array}{l}\mathrm{k}_{2}-\text { the } Z \text {-boson exchange interaction from nucleon axial-vector } \\
\text { currents }\left(A_{n} V_{e}\right)\end{array}$ & 0.0140 & 0.0140 & 0.0111 & 0.0138 \\
$\begin{array}{l}\mathrm{k}_{\mathrm{hf}}-\text { the combined action of the hyperfine interaction and spin- } \\
\text { independent } Z \text { exchange }\end{array}$ & 0.0049 & 0.0078 & 0.0084 & 0.0067 \\
\hline $\mathrm{k}_{\mathrm{a}}$-anapole moment & 0.0980 & 0.090 & 0.0920 & 0.0954 \\
\hline
\end{tabular}

Let us underline that the values of the weak charge are firstly predicted by us for ${ }^{137} \mathrm{Ba}$ and ${ }^{173} \mathrm{Yb}$ atoms. The analysis of results shows that in principle a majority of theoretical approaches provides physically reasonable agreement with the Standard model data, but the important question is how much exact this agreement. In our opinion, however, the prŭcised estimates indicate on the tiny deviation from the Standard model. So, we presented the new effective theoretical approach for sensing hyperfine structure parameters, scalar-pseudoscalar interaction constant and parity non-conservation effect in heavy atomic and nuclear systems, based on the combined QED perturbation theory formalism and relativistic nuclear mean-field theory. Some received data of estimating these constants directly indicate on the necessity of new adequate prŭcised experiments. The rare-earth elements are especially interesting as they have very complicated spectra of autoionization resonances (with very unusual from physical point of view their behavior in a weak electric and laser fields; the known effect of giant broadening [4]). The elementary comments shows that the perspectives of the PNC experiments with Stark pumping of the individual states in the rare-earth atoms (and probably more effective multicharged ions of these elements) and simultaneously polarized laser field dressing (with a cold-atom fountain or interferometer) could provide comfortable conditions for prŭcised observation of the weak effects. 
The estimated values of the weak charge $\mathrm{Q}_{\mathrm{w}}$ and final PNC amplitudes

(in units $10^{-11} \mathrm{iea}_{\mathrm{B}}\left(-\mathrm{Q}_{\mathrm{W}}\right) / \mathrm{N}$ ) for different heavy atoms, predicted in different approaches

\begin{tabular}{|c|c|c|c|c|c|c|c|}
\hline Contribution & $\begin{array}{c}\mathrm{E}_{\mathrm{PNC}} \\
\mathrm{Q}_{\mathrm{W}} \\
\end{array}$ & N-QED & MCDF & $\begin{array}{l}\text { MBPT- } \\
\text { DF }\end{array}$ & $\begin{array}{l}\text { MCDF- } \\
\text { QED }\end{array}$ & $\begin{array}{c}\text { RHF+Breit+ } \\
\text { Correlation }\end{array}$ & $\mathrm{RCC}$ \\
\hline${ }^{85} \mathrm{Rb} \mathrm{5s-6s}$ & $\mathrm{E}_{\mathrm{PNC}}$ & -0.1318 & -0.135 & - & - & -0.134 & - \\
\hline${ }^{133} \mathrm{Cs} 6 \mathrm{~s}-7 \mathrm{~s}$ & $\mathrm{E}_{\mathrm{PNC}}$ & -0.8985 & $\begin{array}{l}-0.935 \\
-0.905\end{array}$ & $\begin{array}{l}-0.897 \\
-0.904\end{array}$ & $\begin{array}{l}-0.8981 \\
-0.9055\end{array}$ & $\begin{array}{l}-0.898 \\
-0.910 \\
-0.902\end{array}$ & $\begin{array}{l}-0.9054 \\
-0.899\end{array}$ \\
\hline 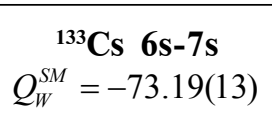 & $\mathrm{Q}_{\mathrm{W}}$ & -72.62 & $\begin{array}{l}-69.78 \\
-71.09\end{array}$ & $\begin{array}{l}-72.69 \\
-72.18\end{array}$ & $\begin{array}{l}-72.65 \\
-72.06\end{array}$ & $\begin{array}{l}-72.66 \\
-71.70 \\
-72.42\end{array}$ & $\begin{array}{l}-72.06 \\
-72.58\end{array}$ \\
\hline${ }^{137} \mathrm{Ba}^{+} 6 \mathrm{~s}-5 \mathrm{~d}_{3 / 2}$ & $\mathrm{E}_{\mathrm{PNC}}$ & -2.385 & - & -2.35 & - & -2.34 & -2.46 \\
\hline 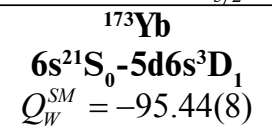 & $\begin{array}{l}\mathrm{E}_{\mathrm{PNC}} \\
\mathrm{Q}_{\mathrm{w}}\end{array}$ & $\begin{array}{l}-97.07 \\
-92.31\end{array}$ & $\begin{array}{l}- \\
-\end{array}$ & - & $\begin{array}{l}- \\
-\end{array}$ & $\begin{array}{l}- \\
-\end{array}$ & $\begin{array}{l}- \\
-\end{array}$ \\
\hline${ }^{205} \mathrm{Tl} 6 \mathrm{p}_{1 / 2}-6 \mathrm{p}_{3 / 2}$ & $\mathrm{E}_{\mathrm{PNC}}$ & 26.5114 & -26.75 & -26.5 & - & - & - \\
\hline $\begin{array}{c}{ }^{205} \mathbf{T l} \mathbf{6} \mathbf{p}_{1 / 2} \mathbf{-} \mathbf{6} \mathbf{p}_{3 / 2} \\
Q_{W}^{S M}=-116.81(4)\end{array}$ & $\mathrm{Q}_{\mathrm{w}}$ & -116.15 & -112.4 & -116.2 & - & - & - \\
\hline${ }^{210} \mathrm{Fr} 7 \mathrm{~s}-8 \mathrm{~s}$ & $\mathrm{E}_{\mathrm{PNC}}$ & -15.481 & - & - & -15.46 & - & - \\
\hline${ }^{223} \mathrm{Fr} 7 \mathrm{~s}-8 \mathrm{~s}$ & $\mathrm{E}_{\mathrm{PNC}}$ & -15.515 & - & - & -15.49 & - & - \\
\hline${ }^{226} \mathrm{Ra}^{+} 7 \mathrm{~s}-6 \mathrm{~d}_{3 / 2}$ & $\mathrm{E}_{\mathrm{PNC}}$ & -44.016 & - & - & - & - & - \\
\hline
\end{tabular}

Note: (SM) - Standard Model;

Authors would like to thank Prof. V. D. Rusov, Prof. A. V. Glushkov, Prof. V. N. Pavlovich, Prof. A. V. Tjurin, Prof. V. I. Vysotskii, Prof. T. N. Zelentsova for useful comments and advises. The useful remarks of the anonymous referee are very much acknowledged too.

\section{References}

1. Grojean C., New approaches to electroweak symmetry breaking// Physics -Uspekhi. - 2007. Vol.50. - P.3- 42; Review of Particle Properties, Particle Physics Booklet (AIP). - July, 1996.

2. Shabalin E. P., What future for $\mathrm{CP}-$ and $\mathrm{T}$-violation studies and CPT-invariance tests?//Physics- Uspekhi. - 2001. - Vol.171. - P.951-976.

3. Grant I. P., Relativistic Quantum Theory of Atoms and Molecules. - Oxford, 2008. - 650P.

4. Glushkov A. V., Relativistic Quantum Theory. Quantum, mechanics of Atomic Systems. - Odessa: Astroprint, 2008. - 900P.

5. Khriplovich I. B., Parity Nonconservation in Atomic Phenomena. - Gordon and Breach, Philadelphia, 1991. - 250P.

6. Grojean C., New approaches to electroweak symmetry breaking// Physics-Uspekhi. - 2007. - Vol. 177. - P.3-42.

7. Khriplovich I. B., Discovery of anapole moment// Physics-Uspekhi. - 1997. - Vol.167. - 1214-1216.

8. Auerbach N., Search for electric dipole moments in atoms of radioactive nuclei// J. Phys. G: Nucl. Part. Phys. - 2008. - Vol.35. - P. 014040.

9. Safronova M. S., Rupsi Pal, Jiang D., Kozlov M. G., Johnson W. R., Safronova U. I., New directions in atomic PNC// Nucl. Phys.A. - 2009. - Vol.827. P.411-413.

10. Khetselius O.Yu., Hyperfine structure of spectral lines of the heavy atoms and multicharged ions. Odessa: Astroprint, 2008. - 210P.

11. Gaigalas G., Gaidamauskas E., Jonsson P., Multiconfiguration Dirac-Hartree-Fock calculations for the hyperfine-structure parameters and the scalar-pseudoscalar interaction constant of ${ }^{133} \mathrm{Cs} / /$ Journal of Physics CS. - 2008. - Vol.130. P. 012008 .

12. Nagasawa T., Haga A., Nakano M., Hyperfine splitting of hydrogenlike atoms based on relativistic mean field theory// Phys.Rev.C. - 2004. - Vol.69. P. 034322:1-10.

13. Bouchiat M. A., Linear Stark effect in dressed atoms as a signal to measure a nuclear anapole moment with a cold-atom fountain or interferometer// Phys.Rev. Lett. - 2007. - Vol.98. - P.043003.

14. Tomaselli M., Kuhl T., Seelig P., Holbrow C. and Kankeleit E., Hyperfine splittings of hydrogenlike ions and the dynamic-correlation model for onehole nuclei// Phys.Rev.C. - 1998. - Vol.58, N3. P.1524-1534.

15. Tomaselli M., Schneider S. M., Kankeleit E., Kuhl T., Ground state magnetization of ${ }^{209} \mathrm{Bi}$ in a dynamiccorrelation model// Phys.Rev.C. - 1995. - Vol.51, N6. - P.2989-2997. 
16. Labzowsky L. N., Johnson W. R., Soff G., Schneider S. M., Dynamic proton model for the hyperfine structure of H-like ion ${ }^{209} \mathrm{Bi}^{+82} / /$ Phys. Rev.A. 1995. - Vol.51, N6. - P.4597-4602.

17. Bieron J., Pyykko P., Degree of accuracy in determining the nuclear electric quadrupole moment of radium//Phys.Rev. A. - 2005. - Vol.71. P.032502.

18. Porsev S. G., Rakhlina Yu.G., Kozlov M. G., Nonconservation of spatial parity in atomic ytterbium// JETP Lett. - 1995. - Vol.61. - P.449-453.

19. Dzuba V. A., Flambaum V. V., Sushkov O. P., Polarizabilities and parity nonconservation in the $\mathrm{Cs}$ atom and limits on the deviation from the standard electroweak model//Phys.Rev.A. - 1997-Vol.56. P.R4357-4360.

20. Safronova M. S., Johnson W. R., Derevianko A. Relativistic many-body calculations of energy levels, hyperfine constants, electric-dipole matrix elements, and static polarizabilities for alkali-metal atoms// Phys.Rev.A. - 1999. - Vol.60. - P.044103.

21. Bennett S. C., Roberts J. L., Wieman C. E., Measurement of the dc Stark shift of the $6 S-7 S$ transition in atomic caesium// Phys. Rev.A. - 1999. - Vol.59. P.3254-3260.

22. Dzuba V. A., Flambaum V. V., Off-diagonal hyperfine interaction and parity nonconservation in cesium// Phys.Rev.A. - 2000. - Vol.62. - P.052101.

23. Johnson W. R., Bednyakov I., Soff G., Vacuum-polarization corrections to the parity-nonconserving $6 s-7 s$ transition amplitude in ${ }^{133} \mathrm{Cs} / /$ Phys. Rev.Lett. 2001. - Vol.87. - P. 233001.

24. Dzuba V. A., Harabati C., Johnson W. R., Safronova $\mathrm{M}$. S., Breit correction to the parity-nonconservation amplitude in cesium//Phys.Rev.A. - 2001. Vol.63. - P.044103.

25. Kozlov M. G. , Porsev S. G., Tupitsyn I. I., High-Accuracy calculation of $6 s-7 s$ parity-nonconserving amplitude in Cs//Phys.Rev.Lett. - 2001. - Vol.86. P.3260-3263.

26. Johnson W. R., Sapistein J., Blundell S. A., Atomic structure calculations associated with PNC experiments in atomic caesium // Phys. Scripta T. 1993. - Vol.46. - P.184-192.

27. Vasilyev A. A., Savukov I. M., Safronova M. S., Berry H. G., Measurement of $6 s-7 p$ transition probabilities in atomic Cs and revised value for the weak charge $\mathrm{Q}_{\mathrm{w}} / /$ Phys.Rev.A. - 2002. - Vol. 66. - P.020101.

28. Johnson W. R., Safronova M. S., Safronova U. I., Combined effect of coherent $\mathrm{Z}$ exchange and hyperfine interaction in parity-nonconserving interaction//Phys.Rev.A-2003. - Vol. 67. - P.062106.

29. Shabaev V. M., Tupitsyn I. I., Pachucki K., Plunien G., Yerokhin V. A., Radiative and correlation effects and parity-nonconserving transition amplitude in heavy alkali-metal atoms// Phys.Rev.A. - 2005. Vol.72. - P.062105.
30. Safronova M. S., Johnson W. R., Safronova U. I., Cowan T. E., Relativistic many-body theory calculation of the Stark-induced amplitude of the 6p$7 \mathrm{p}$ transition in thalium//Phys. Rev.A. - 2006. Vol.74. - P.022504.

31. Dzuba V. A., Flambaum V. V., Safronova M. S., Breit interaction and parity-nonconservation in manyelectron atoms//Phys.Rev.A. - 2006. - Vol.73. P.022112.

32. Glushkov A. V., Ambrosov S. V., Khetselius O.Yu., et al, QED calculation of the super heavy elements ions: energy levels, radiative corrections and hfs for different nuclear models// Nucl. Phys.A.: Nucl.and Hadr. Phys. - 2004. - Vol.734. - Pe 21-28.

33. Kuchiev M.Yu., Flambaum V. V., Radiative corrections to parity nonconservation in atoms and test of the standard model// J. Phys. B. - 2003. - Vol.36. P. R191-222.

34. Johnson W. R., Safronova M. S., Safronova U. I., Combined effect of coherent $\mathrm{Z}$ exchange and the hyperfine interaction in the atomic parity-nonconserving interaction//Phys. Rev. A. - 2003. Vol.67. - P.062106.

35. Serot B. D., Walecka J. D. , Advances in Nuclear Physics Vol. 16: The Relativistic Nuclear Many Body Problem. Plenum Press, New York, 1986.

36. Sahoo B. K., Gopakumar G., Chaudhuri R. K. , Das B. P., Merlitz H., Mahapatra U. S., Makherjee D., Magnetic dipole hyperfine interactions in ${ }^{137} \mathrm{Ba}^{+}$ and the accuracies of neutral weak interaction matrix elements//Phys.Rev.A-2003. - Vol.68. - P.040501.

37. Derevianko A., Porsev S. G., Dressing lines and vertices in calculations of matrix elements with the coupled-cluster method and determination of Cs atomic properties// Phys.Rev. A. - 2005. Vol.71. - P.032509.

38. Glushkov A. V., Khetselius O.Yu., Ambrosov S. V. et al, QED calculation of heavy ions with account for the correlation, radiative and nuclear effects// Recent Advances in Theory of Phys. and Chem. Systems (Berlin, Springer). - 2006. - Vol.15. P.285-300.

39. Glushkov A. V., Khetselius O.Yu., Lovett L., et al, Gauge-invariant QED perturbation theory approach to calculating nuclear electric quadrupole moments, hyperfine structure constants for heavy atoms and ions// Frontiers in Quantum Systems in Chemistry and Physics (Berlin, Springer). - 2008. - Vol.18. - P.505-522.

40. Khetselius O.Yu., On sensing nuclei of the lanthanide isotopes by means of laser spectroscopy of hyperfine structure ${ }^{165} \mathrm{Ho},{ }^{169} \mathrm{Tm} / /$ Sensor Electr. Microsyst. Techn. - 2008. - N2. - P.5-9.

41. Khetselius O.Yu., On possibility of sensing nuclei of the rare isotopes by means of laser spectroscopy of hyperfine structure// Sensor Electr. Microsyst. Techn. - 2008. - N3. - P.28-33.

42. Khetselius O.Yu., Relativistic calculating the hyper- 
fine structure parameters for heavy-elements and laser detecting the isotopes and nuclear reaction products//Phys. Scripta T. - 2009. - Vol.135. P. 014023.

43. Khetselius O.Yu., On sensing nuclei of the ${ }^{207} \mathrm{Bi}$ $\&^{207} \mathrm{~Pb}$ isotopes by means of laser spectroscopy of hyperfine// Sensor Electr. and Microsyst. Techn. 2009. - N2. - P.26-29.

44. Khetselius O.Yu., Relativistic perturbation theory calculation of the hyperfine structure parameters for some heavy-element isotopes//Int. Journ. of Quantum Chemistry. - 2009. - Vol.109. - P. 3330-3335. 